\title{
Qualitative and quantitative analysis of phytochemicals of crude extracts of Ageratina adenophora leaves
}

\author{
Muslek Uddin Mazumder, P. Khazeo, K. Nusalu Puro, Rosamund Jyrwa, Nungshioba Jamir, \\ Lalzikpuii Sailo*
}

Department of Pharmacy, Regional Institute of Paramedical and Nursing Sciences, Zemabawk 796017, Mizoram, India

Corresponding author: zikpuii08@gmail.com

\begin{abstract}
Qualitative and quantitative analysis of bioactive constituents of a plant is necessary for determination of potential pharmacological activity. In this study, the qualitative and quantitative analysis of the petroleum ether, chloroform and methanolic extract of Ageratina adenophora leaves were performed. A. adenophora, also called Eupatorium adenophorum, belongs to the family Asteraceae and it is an invasive species in many tropical and subtropical countries, including northeastern India, China, Sri Lanka, and Nigeria. The plant has high reproductive capacity which is partly due to the well-developed root system. From the roots, important bioactive compounds such as benzofuran derivatives, chromene derivative and a monoterpene glucoside and sesquiterpenoid have been identified. Qualitative phytochemical analysis in the present study revealed the presence of carbohydrates, alkaloids, phenols, flavonoids, xanthoprotein, glycosides, tannins, steroids and terpenoids. Quantification of the total tannins, total alkaloids and total phenols were determined for the methanolic extracts of the leaves. High amount of tannins and phenols was detected.
\end{abstract}

Keywords: Phytochemical, quantitative, bioactive, pharmacological, phenols.

\section{INTRODUCTION}

In the age of orthodox pharmacotherapy, herbal prescriptions gain an interest in the past decades. Although there is often lack of evidence for their therapeutic efficacy and toxicological effects, the use of herbal medicines increasing in a considerable extent. As per World Health Organization (WHO), $80 \%$ of world total population mainly in underdeveloped and developing countries depends on the use of traditional herbal medicines for their primary healthcare needs. The traditional medicines are having its greater acceptance because of easy availability, less or minimum unwanted side effects and costeffective nature. The therapeutic effects of herbal medicines are mainly due to the presence of phytochemicals in the form of flavonoids, alkaloids, sterols, terpenoids, phenolic acids, stilbenes, lignans, tannins and saponins (Nyamai et al., 2016).

Twenty-five years prior to 2007, approximately one half of all licensed drugs were either from natural origin or synthetic products of natural drug (Kennedy and
Wightman, 2011). Depending upon species and genus, the secondary metabolites also differ and secondary metabolites as such do not play any role in primary metabolic process but increase the plants ability to survive and overcome any local challenges by interacting with their environment (Harborne, 1993). Often the primary goal of these secondary metabolites is feeding deterrence, due to their bitter or toxic taste to herbivores and the toxicity sometimes leads to the central and peripheral nervous system effects (Rattan, 2010). The phytochemicals found in plants acts as a defense against diseases and these are natural bioactive compounds (Habila et al., 2011).

Ageratina adenophora, previously known as Eupatorium adenophorum Spreng., is a perennial weedy shrub native to Mexico and it can grow up to $3 \mathrm{~m}$ in height (Heystek et al., 2011; Kluge, 1991; Sun et al., 2004; Wang and Wang, 2006). A. adenophora contains bioactive secondary metabolites. Previously, different classes of chemicals including essential oils, phenyl propanoids, flavonoids, (mono-, sesqui-, di- and tri-) terpenoids, cou- 
marins, sterols and alkaloids had been reported from this species (Ahluwalia et al., 2014; He et al., 2008; Li et al., 2008; Yan et al., 2006; Pala-Paul et al., 2002; Wang et al., 2016). 7-hydroxydehydrotremetone, an abundant compound isolated from $A$. adenophorais having significant broad-spectral inhibitory activity against various fungal strains (Zheng et al., 2018). 2 $\alpha$-methoxyl-3 $\beta$-methyl-6(acetyl-O-methyl)-2,3-dihydrobenzofuran (thymol type monoterpene), eupatorenone and 3-hydroxymuurola-4,7 (11)-dien-8-one, these three compounds are having in vitro bacteriostatic activity against three gram-positive bacteria (Luo et al., 2018).

In this study, the qualitative phytochemical screening of $A$. adenophora leaves were performed to determine the bioactive metabolite present in the plant leaves. Quantification of the total tannin content, total phenol content and total alkaloidal content of the methanolic extract of the leaves were performed.

\section{MATERIALS AND METHODS}

\section{Collection and identification of plant materials}

Fresh leaves of Ageratina adenophora plant were collected from in and around Zemabawk campus of Regional Institute of Paramedical and Nursing Sciences, Aizawl, Mizoram, India. The identity of the plant was authenticated by a taxonomist at the Botanical Survey of India, Shillong. A voucher specimen has been deposited in the Department of Pharmacy, RIPANS, with Reference no: BSI/ERC/TECH/Plant Iden./2018/136.

\section{Preparation of plant extracts}

The extraction of plant metabolites performed by procedure described in Dixit et al. (2005) with slight modifications. The leaves of $A$. adenophora plant were washed thoroughly with distilled water. Plant leaves were dried under shade until becomes completely dried and powdered coarsely by hand. The plant constituents are sequentially extracted using Petroleum ether, Chloroform and Methanol using the Soxhlet apparatus. The powdered leaves were extracted using each solvent to extract soluble matter. The extraction was continued until the extract solution became colorless. The extract was taken into sterile beaker and concentrated by evaporating the solvents in water bath. The dried extract was stored in refrigerator for further analysis.

\section{Phytochemical screening}

The crude methanolic extract of the leaves of $A$. adenophora were used for preliminary qualitative screening of phytochemicals such as alkaloids (Dragendorff's test, Mayer's test, Wagner's test and Hager's test), carbohydrates (Molish test, Fehling's test, Benedict's test and iodine test), phenols and tannins ( $\mathrm{Fecl}_{3}$ test, tannins test, and lead acetate test), flavonoids (alkali test, Shinoda test, lead acetate test and $\mathrm{H}_{2} \mathrm{SO}_{4}$ test), saponins, triterpenoids (Salkowski's test), glycosides (Liebermann's test, Keller-Kilani test), steroids, proteins (Millon's test, ninhydrin test, xanthoprotein test and biuret test) (Thakur et al., 2018; Aziz, 2015; Santhi and Sengottuvel, 2016; Yadav and Agarwala, 2011).

\section{Determination of tannin content}

Total tannin contents of the plant extract were determined by Folin-Ciocalteu method. $0.1 \mathrm{ml}$ of plant extract was taken and transferred to a $10 \mathrm{ml}$ volumetric flask containing $7.5 \mathrm{ml}$ of distilled water and $0.5 \mathrm{ml}$ of FolinCiocalteu phenol reagent (previously diluted ten times with distilled water). $1 \mathrm{ml}$ of $35 \% \mathrm{Na}_{2} \mathrm{CO}_{3}$ solution and volume was made up to $10 \mathrm{ml}$ with distilled water. The mixture was then shaken well and kept it for 30 minutes at room temperature. In the same manner, a set of reference standard solutions of Gallic acid having concentrations $20,40,60,80$ and $100 \mu \mathrm{g} / \mathrm{ml}$ were prepared. Absorbance of the extract solution and standard solutions were measured at $725 \mathrm{~nm}$ against the blank with UVvisible spectrophotometer. Standard curve was plotted for standard and the tannin content was expressed in terms of $\mathrm{mg}$ of gallic acid present per $\mathrm{g}$ of extracts (GAE) g) (Marinova et al., 2005; Singh et al., 2012; Afify et al., 2012; Miean and Mohamed, 2011).

\section{Determination of total phenolic content}

The total phenol concentration in plant extracts were determined using spectrophotometric method. The total phenol content was determined using Folin-Ciocalteu phenol reagent method. $1 \mathrm{ml}$ of extracts and $9 \mathrm{ml}$ of distilled water were transferred to a $25 \mathrm{ml}$ volumetric flask. To it, $1 \mathrm{ml}$ of Folin-Ciocalteu phenol reagent (previously diluted ten times with distilled water) was added and shaken well. After Five minutes $10 \mathrm{ml}$ of $7 \% \mathrm{Na}_{2} \mathrm{CO}_{3}$ solution was added to the mixture. In the same manner, different concentrations of standard gallic acid solutions $(20,40,60,80$ and $100 \mu \mathrm{g} / \mathrm{ml})$ were prepared. Both the sample and standard solutions were incubated for 90 minutes at room temperature. The absorbance of the solutions was taken against the blank at $550 \mathrm{~nm}$ using UV -visible spectrophotometer. The total phenol content was expressed in GAE (mg/g) of extract (Rasool et al., 2011; Ghasemzadeh et al., 2010; Stankovic, 2011).

\section{Determination of total alkaloid content}

$1 \mathrm{mg}$ of plant extract was dissolved in the DMSO. To it, $1 \mathrm{ml}$ of $2 \mathrm{~N} \mathrm{HCl}$ was added and filtered. The solution was transferred to separating funnel and to it $5 \mathrm{ml}$ of bromocresol green solution and $5 \mathrm{ml}$ of phosphate buffer were added. The mixture was shaken vigorously with 1 , 


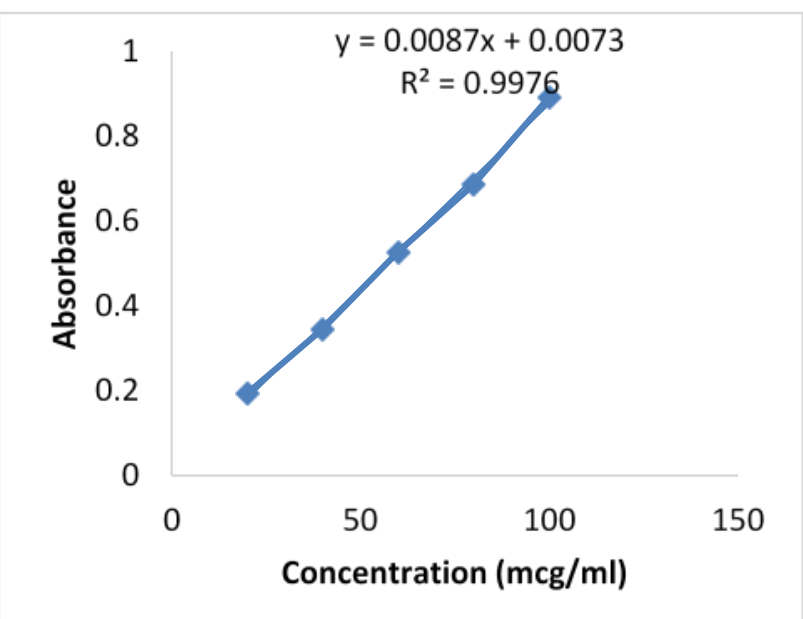

Figure 1: Standard curve for total phenol content.

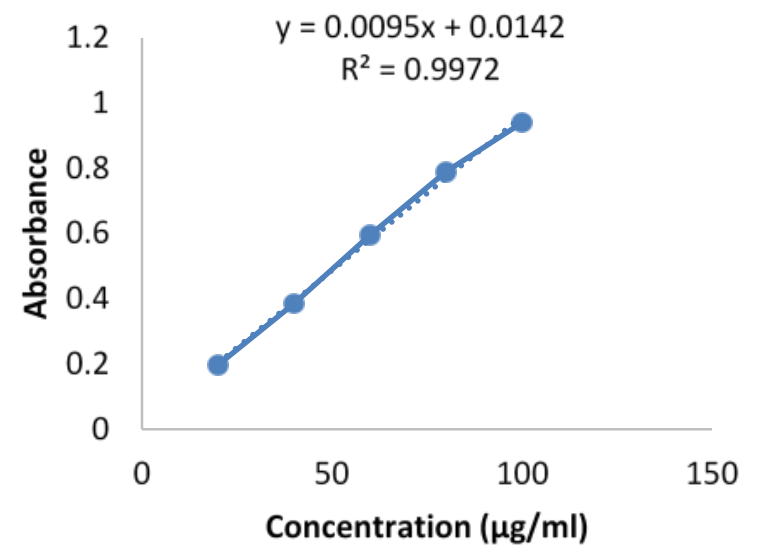

Figure 3: Standard curve for total alkaloidal content.

2, 3 and $4 \mathrm{ml}$ of chloroform and then extracted to a $10 \mathrm{ml}$ volumetric flask and volume was made up to $10 \mathrm{ml}$ with chloroform. In the same manner a set of reference standard solutions of atropine $(20,40,60,80$ and $100 \mu \mathrm{g} / \mathrm{ml})$ were prepared. Absorbances were taken for both sample and standard solutions at $470 \mathrm{~nm}$ against the blank using UV-visible spectrophotometer. Total alkaloid content was expressed in terms of $A E(\mathrm{mg} / \mathrm{g})$ of extract (Shamsa et al., 2008; Rao et al., 2012).

\section{RESULTS}

\section{Extractive yield}

$49 \mathrm{~g}$ of powdered A. adenophora leaves were sequentially extracted using petroleum ether, chloroform and methanol and extractive yields are summarized in Table 1.

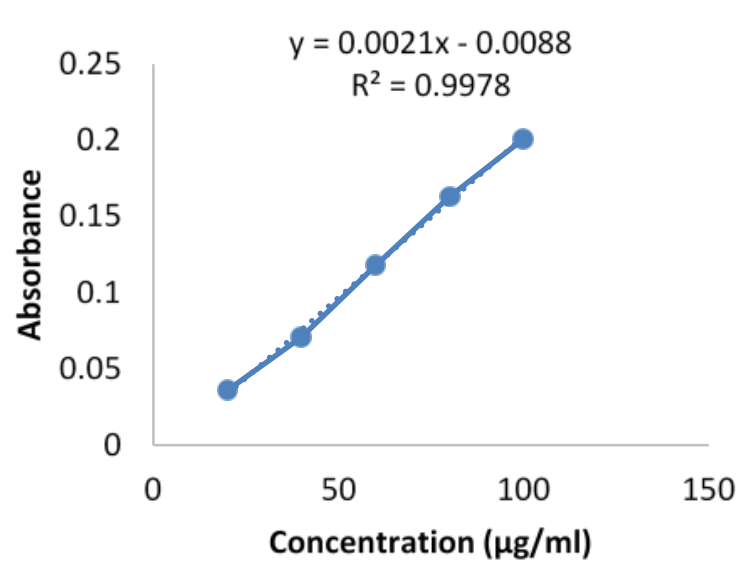

Figure 2: Standard curve for total tannin content.

\section{Qualitative phytochemical analysis}

Methanolic extract of leaves of A. adenophora was investigated for different qualitative phytochemicals and the result obtained were shown in the Table 2.

\section{Quantification of phytochemicals}

Methanolic extract of leaves of $A$. adenophora were investigated for total tannin content, total phenol content and total alkaloid content and the result obtained were shown in the Table 3 . The tannin content of the plant extract was determined using Folin-Ciocalteu reagent method and the concentration of the tannin was found to be $156.59 \pm 0.55$ (GAE/g). The total phenolic content of the plant extract was determined using FolinCiocalteu reagent method and the concentration of was found to be $235.41 \pm 0.72$ (GAE/g).

Table 1: Extractive yield for different solvents from the leaves of Ageratina adenophora.

\begin{tabular}{|c|c|c|}
\hline Sl. No. & Extract & Extractive yield (\%) \\
\hline 1 & Petroleum ether & 5.55 \\
\hline 2 & Chloroform & 3.06 \\
\hline 3 & Methanol & 11.47 \\
\hline
\end{tabular}

Table 2: Result of phytochemical screening of methanolic extract of Ageratina adenophora leaves.

\begin{tabular}{|c|c|c|}
\hline No. & Phyto-constituents & Result \\
\hline 1 & Alkaloids & + \\
\hline 2 & Carbohydrates & ++ \\
\hline 3 & Phenols and tannins & ++ \\
\hline 4 & Flavonoids & ++ \\
\hline 5 & Saponins & - \\
\hline 6 & Triterpenoids & + \\
\hline 7 & Glycosides & ++ \\
\hline 8 & Steroids & + \\
\hline 9 & Proteins (xanthoprotein) & + \\
\hline
\end{tabular}


Table 3: Contents of phytochemicals in the plant extract.

\begin{tabular}{|c|c|c|}
\hline No. & Phytochemicals & $\begin{array}{c}\text { Quantity (mg/g) } \\
\text { Mean } \pm \text { SD }\end{array}$ \\
\hline 1 & Alkaloid & $6.07 \pm 0.16$ \\
\hline 2 & Tannin & $156.59 \pm 0.55$ \\
\hline 3 & Phenol & $235.41 \pm 0.72$ \\
\hline
\end{tabular}

The alkaloid content was determined in the plant extract and expressed in terms of Atropine equivalent as $\mathrm{mg}$ of atropine per $\mathrm{g}$ of plant extract $(\mathrm{AE} / \mathrm{g})$. The concentration of alkaloid was found in extracts are $6.07 \pm 0.16$ $(\mathrm{AE} / \mathrm{g})$. All the standard curves showed strong positive linear correlation(R). As the value of the concentration increases the absorbances also increases.

\section{DISCUSSION}

The qualitative phytochemical screening for the analysis of bioactive metabolites were performed for the methanolic extract of $A$. adenphora leaves in this study and the result obtained is shown in Table 1 . The data obtained revealed that there are various phytochemicals were present in the extract. The data showed that strong positive results found for carbohydrates, phenols, tannins, flavonoids and glycosides. The result for xanthoprotein, alkaloids, steroids and triterpenoids showed positive result.

The study revealed that, various phytochemicals are present in the leaves of A. adenophora and these phytochemicals can be useful in various ways for either mitigation or prevention of diseases. The total phenols, total tannins and total alkaloids were also investigated. There is presence of significant amount of tannins and phenols present in the leaves of $A$. adenophora but the alkaloid is present in lesser amounts as compared to other phytochemicals. Tannins and phenols can be investigated further from this study to utilise in further investigations (Durai et al., 2016; Tambe and Bhambar, 2014).

\section{ACKNOWLEDGEMENT}

The authors wish to acknowledge Dr Chawngthanliana, Director, Regional Institute of Paramedical and Nursing Sciences (RIPANS), and Dr. H. Lalhlenmawia, Head of Department of Pharmacy, RIPANS, Zemabawk, Mizoram for providing the facilities to complete this research work.

\section{REFERENCES}

Afify, A.el-M., El-Beltagi, H.S., El-Salam, S.M., Omran, A.A. (2012). Biochemical changes in phenols, flavonoids, tannins, vitamin $E, \beta$-carotene and antioxidant activity during soaking of three white sorghum varieties.
Asian Pac. J. Trop. Biomed. 2(3), 203-209.

Ahluwalia, V., Sisodia, R., Walia, S., Sati, O.P., Kumar, J., Kundu, A. (2014). Chemical analysis of essential oils of Eupatorium adenophorum and their antimicrobial, antioxidant and phytotoxic properties. J. Pest. Sci. 87, 341-349.

Aziz, M.A. (2015). Qualitative phytochemical screening and evaluation of anti-inflammatory, analgesic and antipyretic activities of M icrocos paniculata barks and fruits. J. Integr. Med. 13(3),173-184.

Durai, M.V., Balamuniappan, G., Anandalakshmi, R., Geetha, S., Kumar, M.S. (2016). Qualitative and quantitative analysis of phytochemicals in crude extract of big leaf-Leaf Mahogany (Swietenia macrophylla King.). Int. J. Herbal Med., 4(6), 88-91.

Dixit, P., Ghaskadbi, S., Mohan, H., Devasagayam, T.P.A. (2005). Antioxidant properties of germinated fenugreek seeds. Phytother. Res. 19(11), 977-983.

Ghasemzadeh, A., Jaafar, H.Z.E., Rahmat, A. (2010). Antioxidant activities, total phenolics and flavonoids content in two varieties of Malaysia Young Ginger (Zingiber officinale Roscoe). Molecules. 15, 43244333.

Habila, J.D., Bello I.A., Dzikwe A.A., Ladan Z., Sabiu M. (2011) Comparative evaluation of phytochemicals, antioxidant and antimicrobial activity of four medicinal plants native to Northern Nigeria. Australian Journal of Basic and Applied Sciences. 5(5):537-543.

Harborne, J.R. (1993). Introduction to Ecological Biochemistry. $4^{\text {th }}$ Ed. London: Elsevier.

He, L., Hou, J., Gan, M., Shi, J., Chantrapromma, S., Fun, H.K., Williams, I.D., Sung, H.H.-Y. (2008). Cadinane sesquiterpenes from the leaves of Eupatorium adenophorum. J. Nat. Prod. 71, 1485-1488.

Heystek, F., Wood, A., Neser, S., Kistensamy, Y. (2011). Biological control of two Ageratina species (Asteraceae: Eupatorieae) in South Africa. African Entomology, 19, 208-216.

Kennedy, D.O., Wightman, E.L. (2011). Herbal extracts and Phytochemicals: Plant secondary metabolites and the enhancement of human brain function. Adv. Nutr. 2, 32-50.

Kluge, R. (1991). Biological control of crofton weed, Ageratina adenophora (Asteraceae), in South Africa. Agric. Ecosyst. Envi. 37, 187-191.

Li, Y., Li, Z., Ye, M. (2008). The chemical compositions and their bioactivities in the different parts of Eupatorium adenophorum Spreng. J. Yunnan Agric. Univ. 23, 4246.

Luo, B., Dong, L-M., Xu, Q-L., Xhang, X., Zhang, Q., Liu, WB. (2018). A new monoterpene and anew sesquiterpene from the roots of Ageratina adenophora. Phytochem. Lett. 24, 67-70.

Marinova, D., Ribarova, F., Atanassova, M. (2005). Total phenolics and total flavonoids in Bulgarian fruits and vegetables. J. University Chem. Technol. Metallurgy. 40 (3), 255-260. 
Miean, K.H., Mohamed, S. (2001). Flavonoid (myricetin, quercetin, kaempferol, luteolin, and apigenin) content of edible tropical plants. J. Agric. Food. Chem. 49 (6), 3106-3112.

Nyamai, D.W., Arika W., Ogola, P.E., Njagi, E.N.M., Ngugi, M.P. (2016). Medicinally important phytochemicals: An untapped research avenue. J. Phramacogn. Phytochem. 4(1), 35-49.

Pala-Paul, J., Perez-Alonso, M.J., Velasco-Negueruela, A., Sanz, J. (2002). Analysis by gas chromatography-mass spectrometry of the volatile components of Ageratina adenophora Spreng., growing in the Canary Islands. J. Chromatogr. A 947, 327-331.

Rao, T.M., Rao, B.G., Rao, Y.V. (2012). Antioxidant activity of Spilanthes acmella extracts. Int. J. Phytopharmacol. 3(2), 216-220.

Rasool, N., Rızwan, K., Zubaır, M., Naveed, K.U.R., Imran, I., Ahmed, V.U. (2011). Antioxidant potential of different extracts and fractions of Catharanthus roseus shoots. Int. J. Phytomed. 1(3), 108-114.

Rattan, R.S. (2010). Mechanism of action of insecticidal secondary metabolites of plant origin. Crop. Prot. 29, 913-920.

Santhi, K., Sengottuvel, R. (2016). Qualitative and quantitative phytochemical analysis of M oringa concanensis Nimmo. Int. J. Curr. M icrobiol. App. Sci. 5(1), 633-640.

Shamsa, F., Monsef, H., Ghamooshi, R., Verdian-rizi, M. (2008). Spectrophotometric determination of total alkaloids in some Iranian medicinal plants. Thai. J. Pharm. Sci.; 32: 17-20.

Singh, R., Verma, P.K., Singh G. (2012). Total phenolic, flavonoids and tannin contents in different extracts of Artemisia absinthium. J Intercult Ethnopharmacol. 1 (2), 101-104.
Stankovic, M.S. (2011). Total phenoliccontent, flavonoid concentration and antioxidant activity of Marrubium peregrinum L. extracts. Kragujevac J Sci. 33, 63-72.

Sun, X., Lu, Z., Sang, W. (2004). Review on studies of Eupatorium adenophorum an important invasive species in China. Journal of Forestry Research, 15, 319322.

Tambe, V.D., Bhambar, R.S. (2014). Estimation of total phenol, tannin, alkaloid and flavonoid in Hibiscus tiliaceus Linn. wood extracts. Res. Rev. J. Pharmacogn. Phytochem., 2(4), 41-47.

Thakur, A.V., Ambwani, S., Ambwani, T.K. (2018). Preliminary phytochemical screening and GC-MS analysis of leaf extract of Acacia catechu (I.f.) wild. Int. J. Herbal Med., 6(2), 81-85.

Wang, C.F., Yang, R., Song, L., Ning, B.M., Ouyang, C.B., Cao, A.C., He, L. (2016). Two new highly-oxygenated flavonoid glycosides from Eupatorium adenophorum Spreng. Phytochem. Lett. 16, 245-248.

Wang, R., Wang, Y. (2006). Invasion dynamics and potential spread of the invasive alien plant species Ageratina adenophora (Asteraceae) in China. Diversity Distrib., 12, 397-408.

Yadav, RNS., Agarwala, M. (2011). Phytochemical analysis of some medicinal plants. J. Phytol. 3(12), 10-14.

Yan, Q., Ye, J., Li, H., Cao, A., Chen, Q., Wen, Y., He, L. (2006). Advances in the studies on the chemical components and bioactivity of Eupatorium adenophorum Spreng as an intruding species. J. Beijing Norm. Univ. 42, 70-73.

Zheng, G., Luo, S., Li, S., Hua, J., Li, W., Li, S. (2018). Specialized metabolites from Ageratina adenophora and their inhibitory activities against pathogenic fungi. Phytochemistry, 148, 57-62. 